\title{
Mapping the Potential for Hay Making in Rangelands: A Methodological Proposition
}

\author{
Henry Makuma-Massa, Jane Bemigisha, Beatrice Kyasimire, Eunice Nyiramahoro, \\ John Begumana, Swidiq Mugerwa, Anthony Egeru, and Moses Cho
}

\section{On the Ground}

-We present information useful to various stakeholders, including land managers, agency personnel, practitioners, and researchers, as it presents methodology for

- Determining the best period for hay harvest corresponding to peak productivity of the vegetation in rangelands;

O Estimating the amount of hay available (biomass) at peak productivity, using commonly available satellite imagery; and

$\bigcirc$ Highlighting the best areas for hay production based on grassland availability.

- All of this is done by employing the readily available tools of remote sensing and geographical information system.

Keywords: Climate Change, grasslands, pastoralists, rangelands, geographic information system, remote sensing.

Addressing global environmental change has been on the international agenda for many decades. Climate change, as an "undesirable" consequence of the increased concentration of greenhouse gases in the atmosphere, has remarkably undermined agricultural productivity, translating into alarming levels of food insecurity. ${ }^{1}$ The devastating effects of climate change on agricultural productivity are more pronounced in arid and semi-arid ecosystems. With or without climatic changes, the climate of rangeland ecosystems is characterized by stochastic rainfall events on spatial and temporal scale and high atmospheric temperatures and evaporation rates. ${ }^{2}$ Climate change is exerting more pressure on the functionality and resilience of rangeland systems, yet rangelands support a significant number of the livestock around the world. This is placing the sustainability, productivity, and competitiveness of livestock production systems in rangelands under threat. In Uganda, rangelands account for $43 \%$ of the total land area, and livestock production is the major source of livelihood for over $60 \%$ of households in the rangelands of Uganda. Livestock production in these locations is largely constrained by climatic changes, with devastating effects on forage and water availability leading to variable milk and meat outputs. ${ }^{3}$

Furthermore, climate change and variability has been shown to have negative impacts on livestock birth rates, mortality rates, and meat quality in Uganda. ${ }^{4,5}$ The rapidly increasing population, changes in land use, and alterations in policies regarding pastoralism are constraining pastoral movements, leading to increased transhumant pastoralism, transitions to livestock-crop integration, and commencement of permanent grazing areas. ${ }^{6,7}$ Pastoralists in Uganda who depend on rain-fed pastures find challenges in maintaining herds during prolonged droughts, but they will have burned the previous season's pasture in the belief that better pastures will sprout in the next rainy season. ${ }^{5}$

In the face of climate change and variability with dwindling grazing land, areas available for grazing would have to be effectively managed to ensure a sustainable supply of pasture resources. The trends observed in the pastoral production systems have led to discourse on how to ensure sustainable livestock production amidst pressing climate change and variability patterns. Consequently, hay production has been identified as a key leverage action that will allow pastoral communities to increase livestock productivity and quality and at the same time ensure sustainable income streams and build their resilience to the impacts of climate change and variability. ${ }^{8,9}$ Hay making is advantageous because it ensures that forage, which would have been wasted by burning and rotting, is available in the next season of feed shortage. Hay production also has potential to enhance the income, wealth, and livelihoods of the producer communities if production is stepped up to realize surpluses. The production of hay promotes environmental conservation and sustainable use of rangelands for improved livelihood and set guidelines for the development of appropriate feed resources, which is a key 
objective of rangeland policy. ${ }^{9,10}$ Stimulating community engagement and promotion of adoption of hay production offers an opportunity for livestock farmers to cope with climate-change-induced forage scarcity, but this requires explicit description of the hay production potential in such areas.

Hay production can be optimized when grasses are at their most productive period, and this may become more pressing in the advent of unpredicted climate/weather patterns in African rangelands. However, the lack of sufficient data on hay availability and production in most areas has limited decision-making in the livestock sector in Uganda. There is a paucity of information regarding the hay production potential in the rangelands of Africa. Several studies ${ }^{11,12}$ have highlighted the role of Geographic Information System (GIS) data, particularly remote sensing (RS) data acquired using space-borne platforms, as a cost-effective and rapid means of providing data on pasture quality and quantity at any given period of the year. ${ }^{11,12}$ Information on suitable sites for hay production and the temporal and spatial variations in quantity and quality of hay is particularly deficient. Therefore, the study sought to employ RS and GIS to determine hay production potential and dynamics, developing a methodology for rapidly mapping and establishing the potential of hay production in rangelands.

\section{Study Area}

The study was conducted in the districts of Nakasongola, Nakaseke, and Luwero in the Cattle Corridor of Uganda. The

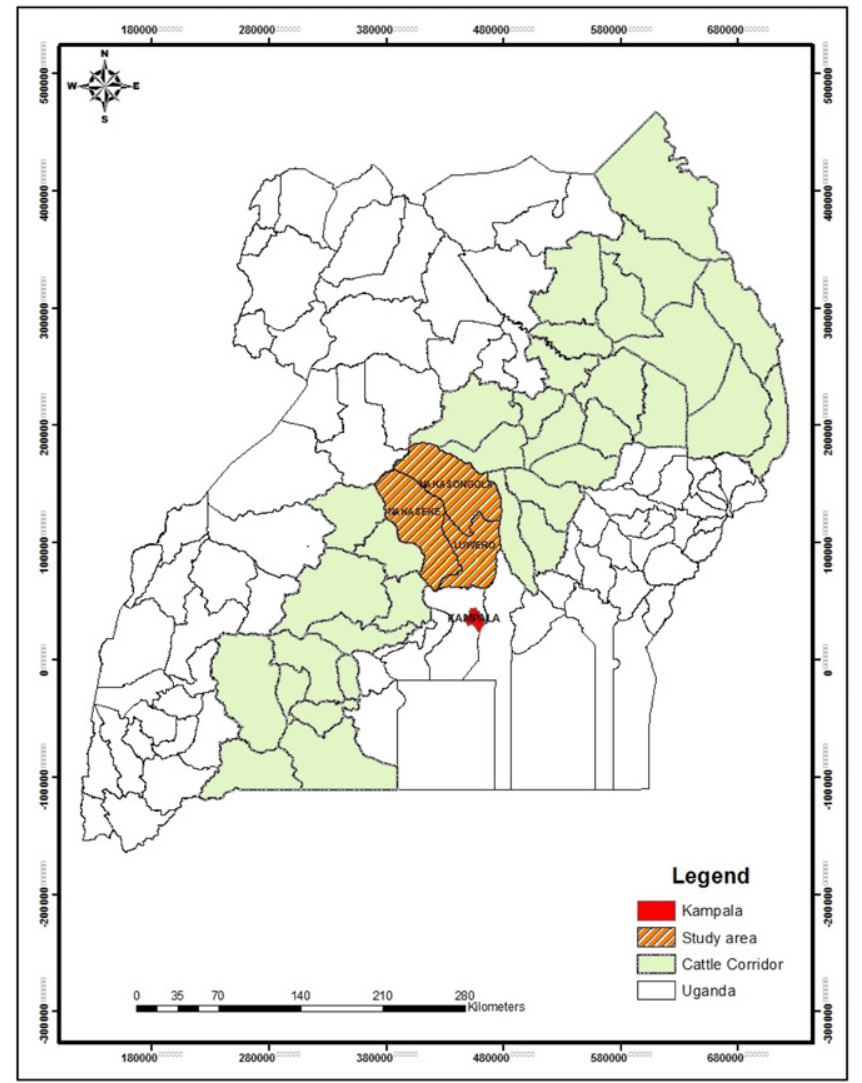

Cattle Corridor of Uganda stretches diagonally from the southwest to northeast of the country (Fig. 1). Nakasongola, Nakaseke, and Luwero are located at $00^{\circ} 57^{\prime} 44.89^{\prime \prime} \mathrm{N}$ and $310^{\circ} 58^{\prime} 03.77^{\prime \prime} \mathrm{E}$, at the central part of the Cattle Corridor of Uganda. The districts receive a bimodal rainfall regime with the first rainy season occurring in the months of March to May and the second in September to November. The mean daily minimum temperature ranges between $15.0^{\circ} \mathrm{C}$ and $20.9^{\circ} \mathrm{C}$, while the mean daily maximum temperature ranges between $25.4^{\circ} \mathrm{C}$ and $33.7^{\circ} \mathrm{C}$. Average humidity ranges from $80 \%$ in the morning to $56 \%$ in the afternoon. The potential evapotranspiration remains high throughout the year $(\sim 130 \mathrm{~mm} /$ month and $\sim 1,586 \mathrm{~mm} /$ annum) and shows less variability than rainfall.

\section{Methods}

\section{Methodological Structure and Interrelationship}

This study set out to determine the optimum period for hay harvest at peak vegetation production and the method for assessing the available hay at peak production (i.e., herbaceous grass biomass). Uganda has a tropical climate with two rainy seasons (March to May and September to November) and two dry periods. The three districts that make up the project area experience this bimodal seasonal calendar. Figure 2 presents a summary of the methodological logical structure and interrelationship that were undertaken to achieve the

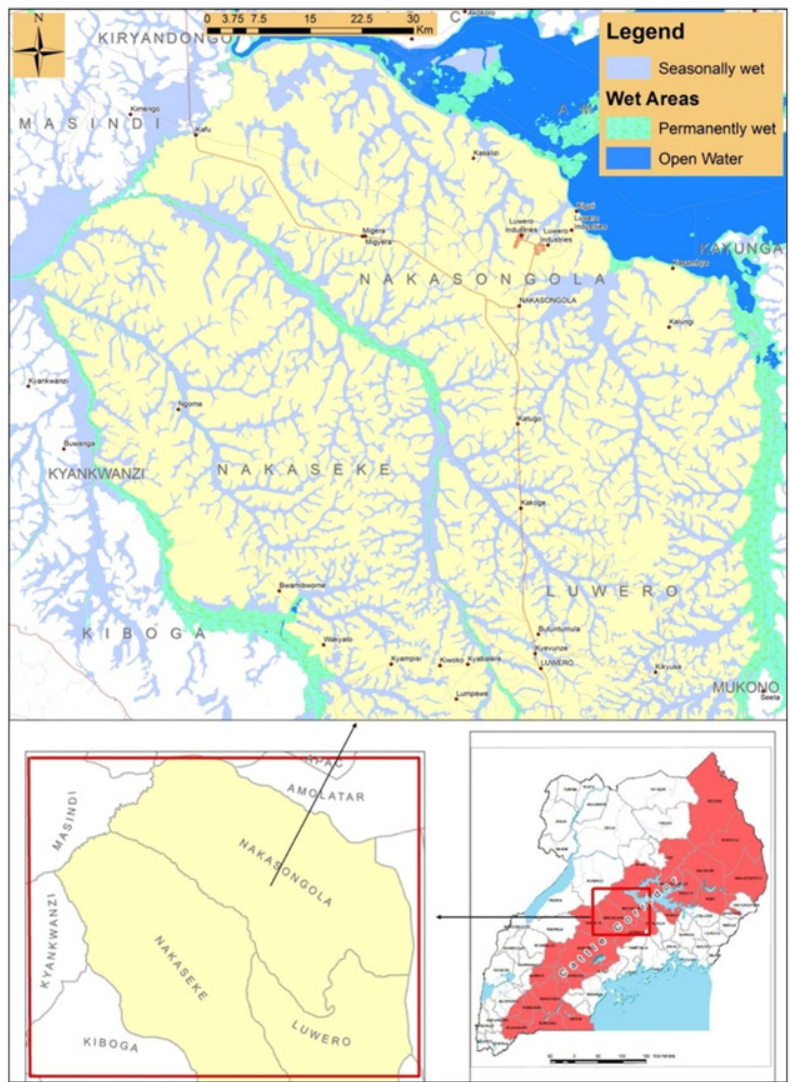

Figure 1. Location of study area. 


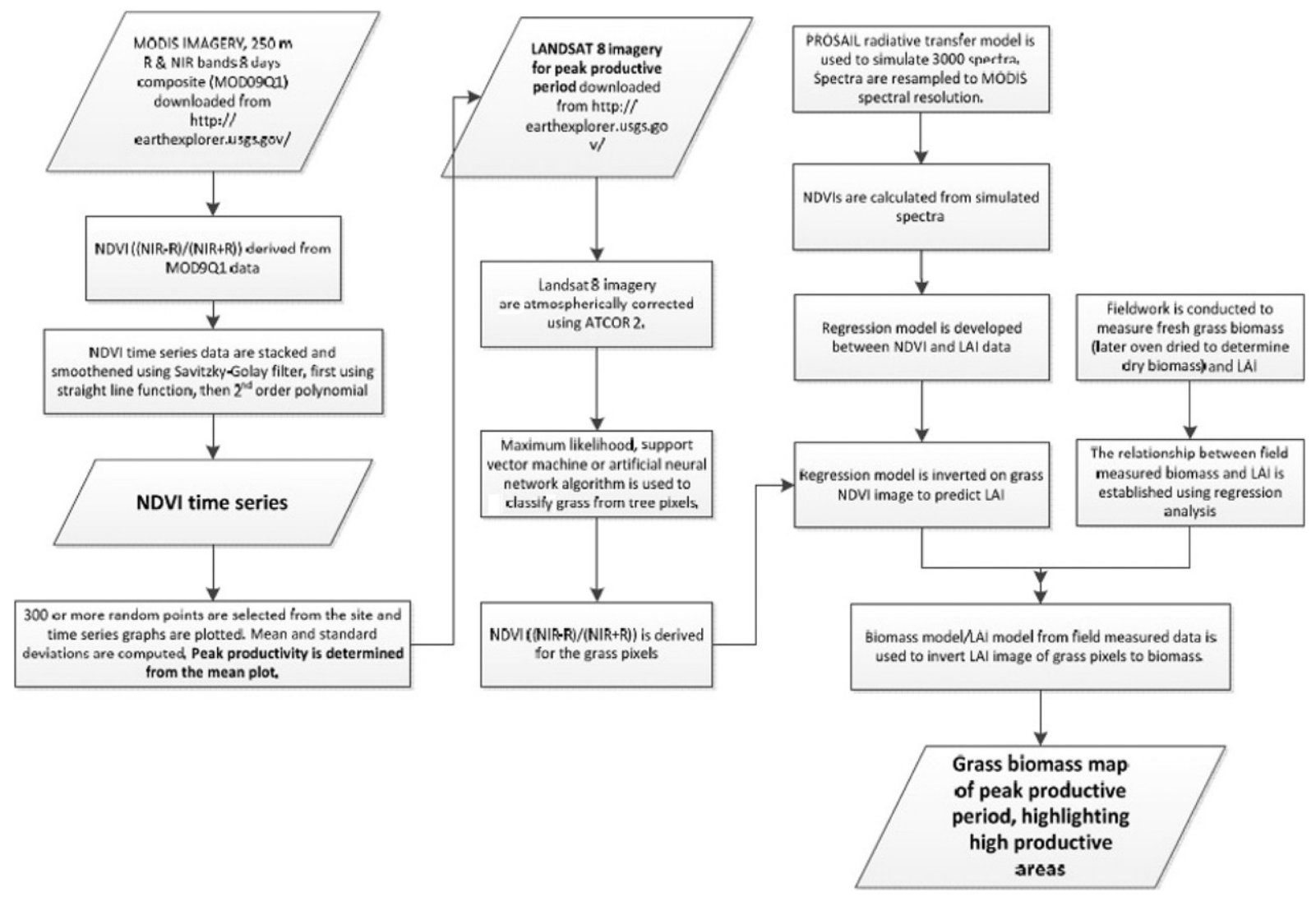

Figure 2. A methodological approach that can help determine the period for hay harvest and potential quantity (biomass) of hay developed.

study's focus. This methodology was used to monitor vegetation production throughout the four seasons and to determine the period of peak vegetation production, which constitutes the best period of hay harvest in the project area.

\section{Modeling Peak Herbaceous Biomass Production}

A time series of 8-day composite Normalized Difference Vegetation Index (NDVI) derived from Moderate Resolution Imagery Spectrometer (MODIS) imagery was used to determine the peak/optimum production period. MODIS imagery is recommended for this purpose because it provides a higher temporal resolution (1 day revisit time) than Landsat 8 (16 days). On the other hand, the higher spatial resolution of Landsat 8 is better suited to determine variability of herbaceous biomass and quality at peak production in the rangelands because of the patchiness often associated with these locations.

The MODIS sensor was launched into space in 1999 aboard the TERRA satellite and in 2002 aboard the AQUA satellite. MODIS provides data at various spatial resolutions, including two bands (red and near infrared [NIR]) at $250 \mathrm{~m}$ and five visible to short-wave infrared (SWIR) bands at $500 \mathrm{~m}$. The MODIS two-band image at $250 \mathrm{~m}$ resolution (MOD09Q1 products - surface reflectance, i.e., atmospherically corrected 8-day composites) is proposed for this project. The images were downloaded from http://earthexplorer.usgs. gov/. The $250 \mathrm{~m}$ resolution provided better spatial variability of grass patches in the project area, whose sizes are generally smaller than $500 \mathrm{~m}$ by $500 \mathrm{~m}$.

The normalized difference vegetation index (NDVI) (NIR-R)/(NIR + R), a well-established RS index or indicator for vegetation productivity, was computed from the MODIS image to determine the peak production. NDVI images for the year (e.g., 2014) were stacked to generate a time series that could be used to monitor the trend in vegetation production. The time series are usually noisy due to the presence of clouds. Therefore, smoothing was required to tease out the trend in vegetation productivity. The Savitzky-Golay filter was used to smooth the NDVI time series. A two-stage smoothing process is proposed, first using a straight line model (one-degree polynomial), followed by a second-degree polynomial smoothing function.

Profiles of 350 randomly selected pixels were extracted from the time series, and the mean and standard deviation of the profiles were computed (e.g., see Fig. 3 for 2014 NDVI profiles). The peak production period was determined from the mean profiles (i.e., the period of maximum NDVIs). The first derivative of the NDVI time series or profile can be used to monitor the changes in NDVI. At peak production (i.e., maximum turning point of the time series), the first derivative is equal to zero. The first derivative profile can be produced using the first difference transformation of the NDVI profile. 

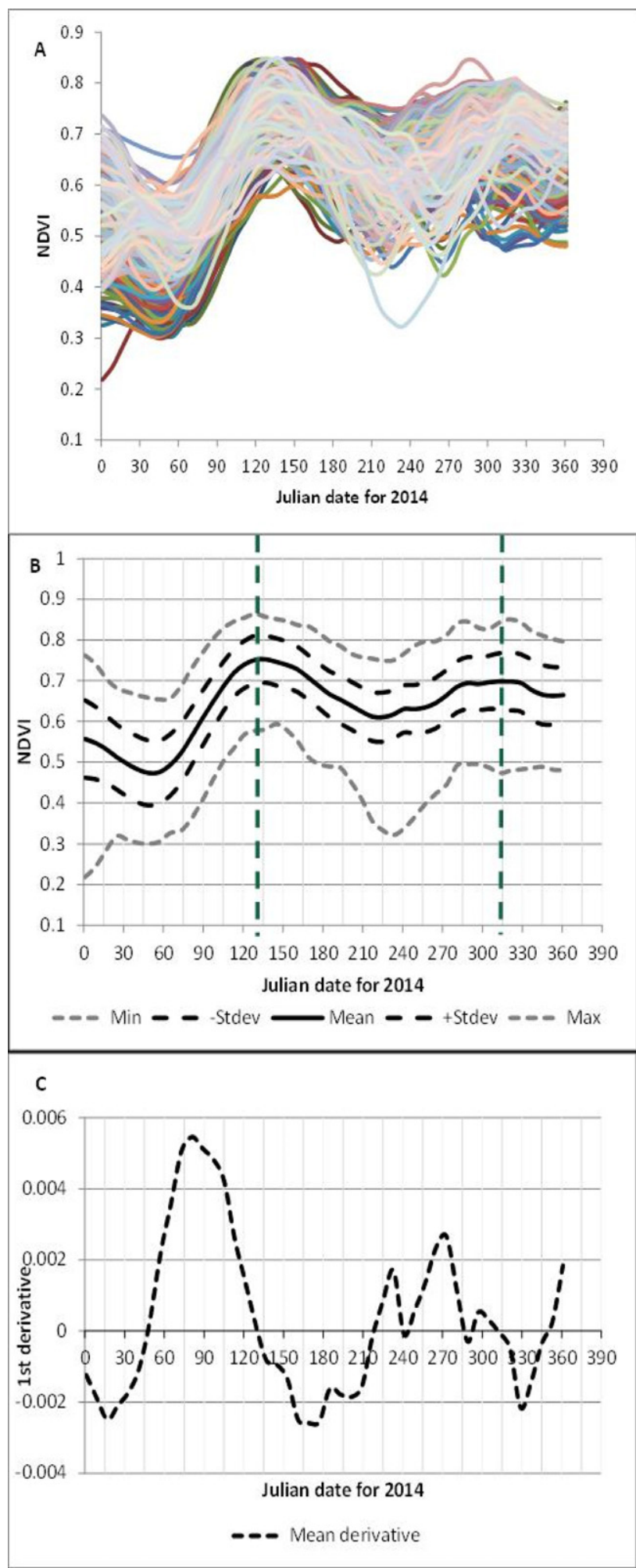

Graph 1
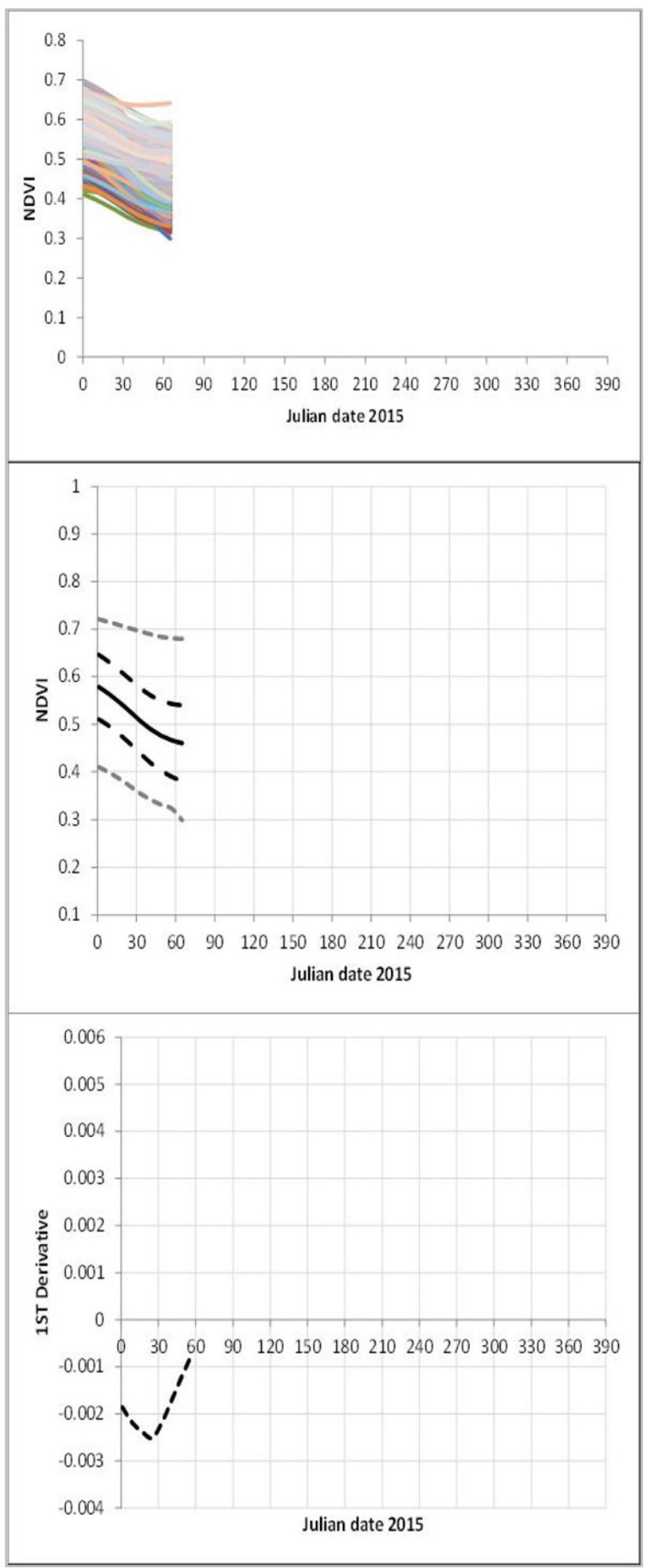

Graph 2

Figure 3. Graph 1 is the 2014 NDVI time series analysis and 2015 NDVI time series analysis.

\section{Modeling Hay Quantity (Spatial Variability) at Peak Vegetation Productivity}

An eight-step approach was established for assessing grass biomass maps (spatial variability of biomass) at the peak production period of the vegetation in the Cattle Corridor: Landsat 8 image acquisition; Landsat 8 atmospheric correction; cloud removal; vegetation type cover classification; field sampling of leaf area index (LAI) and grass biomass; radiative transfer 


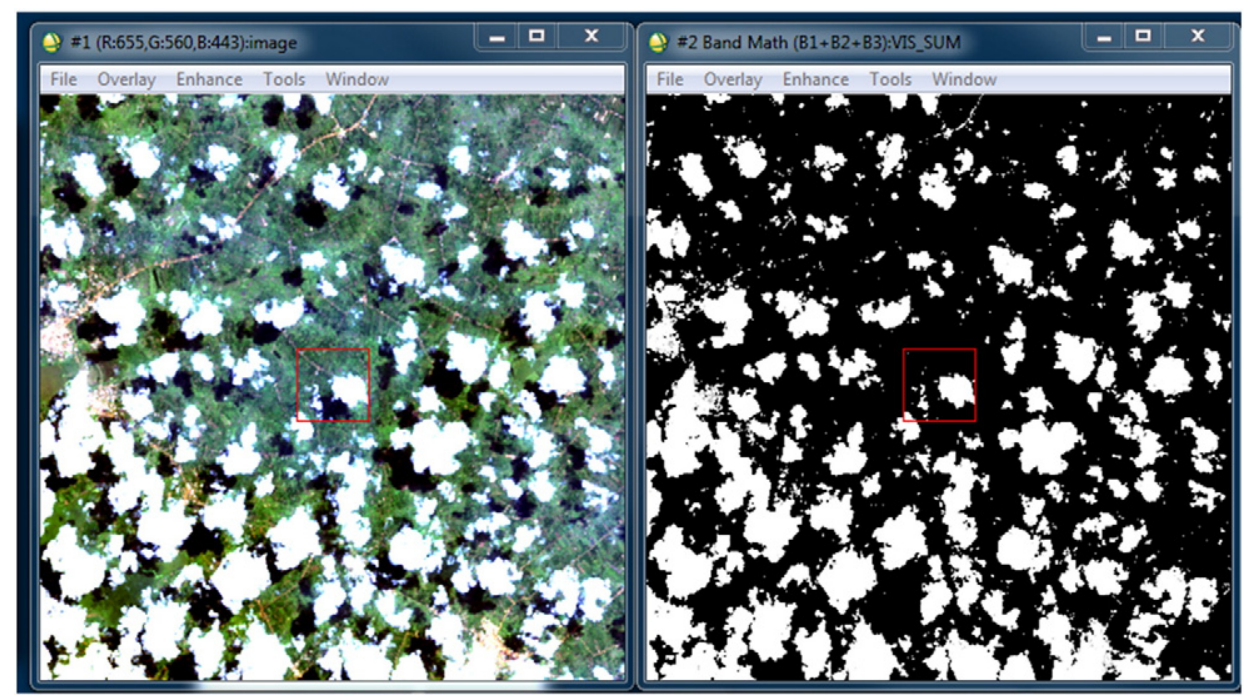

Figure 4. Cloud removal using thresholding of sum of red, green, and blue bands (picture on the right). R indicates red; G, green; B, blue.

modeling and developing predictive equation for LAI; predicting LAI on the Landsat image; and predicting grass biomass.

\section{Results}

\section{Part I: Best Period for Hay Harvesting and Available} Hay Using Remote Sensing Data

A first derivative profile of the mean NDVI profile for 2014 was used to determine the maximum production (maximum turning point of the NDVI profile) date (i.e., where the profile

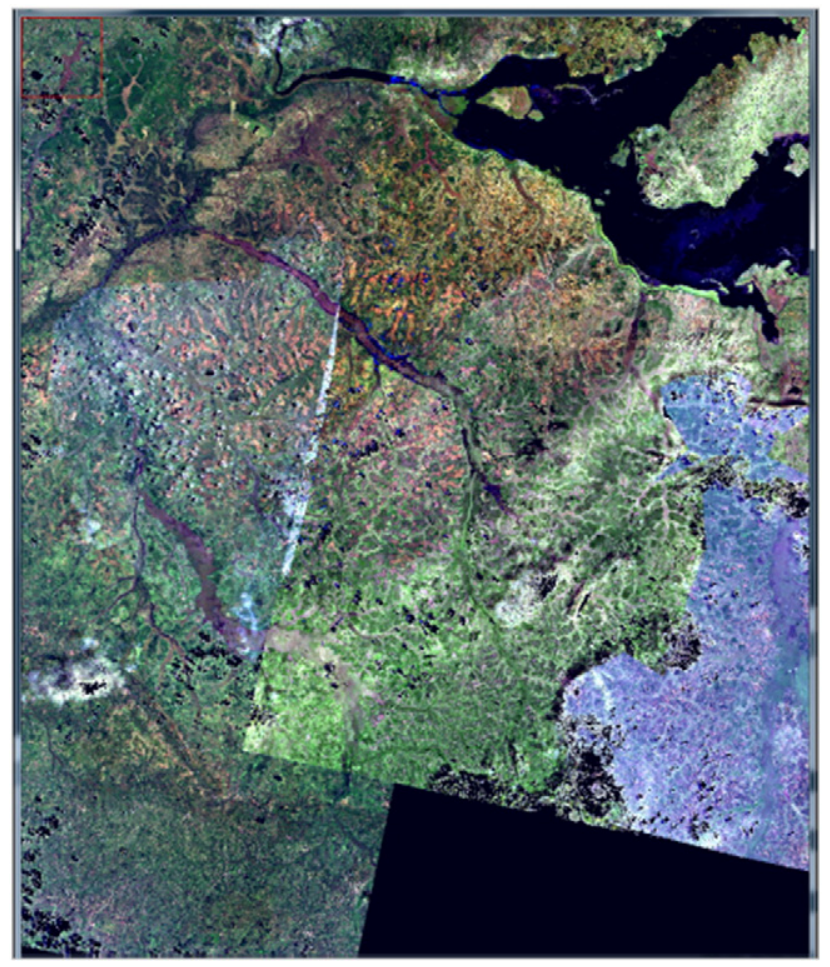

Figure 5. Mosaic of two image scenes acquired on 29 October and 16 November 2014 after cloud removal. cuts the horizontal axis at slope $=0$ ). Potential hay harvesting (NDVI/biomass) was found to peak on the $130^{\text {th }}$ day and $320^{\text {th }}$ day (Fig. 3). Vertical lines in the graphs indicate dates of maximum vegetation productivity within the project site. Graph 2 of Figure 3 shows the evolution of the NDVI profile for 2015. Monitoring the evolution of the 2015 NDVI profile can be used to determine the maximum turning point or peak production for this year.

In summary, determining the best period for hay harvest includes image acquisition and pre-processing, creation of

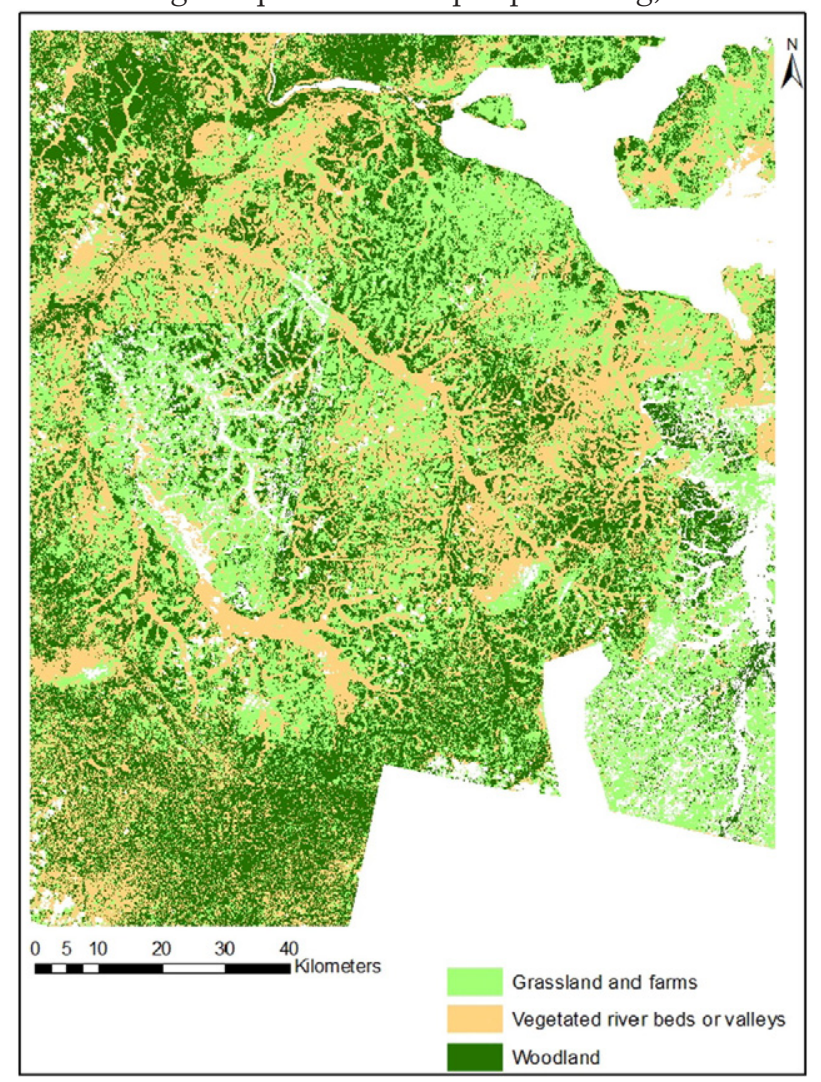

Figure 6. Vegetation type classification in the project site. 
NDVI time series images, and determination of peak production.

\section{Part II: Process of Modeling Hay Quantity (Spatial Variability) at Peak Vegetation Productivity Step 1 - Landsat 8 Image Acquisition}

LANDSAT 8 Operational Land Imager (OLI) images were proposed for this modeling of grass biomass because LANDSAT 8 OLI images are obtained from a medium-resolution sensor $(30 \mathrm{~m})$ consisting of 11 bands in the visible, NIR, SWIR, and thermal infrared (TIR), although the TIR is not required for this research. The data obtained were used to obtain patterns in vegetation and grass conditions in the study area. Landsat 8 images for the peak production period were downloaded from http:// earthexplorer.usgs.gov/. ${ }^{13}$ Two main scenes made up the area (171059 and 172059). Images of different dates were used because of the presence of clouds.

\section{Step 2 - Landsat 8 Atmospheric Correction}

The images required cloud removal and atmospheric correction. Atmospheric/Topographic Correction for Satellite Imagery (ATCOR 2/3) was used for atmospheric correction.

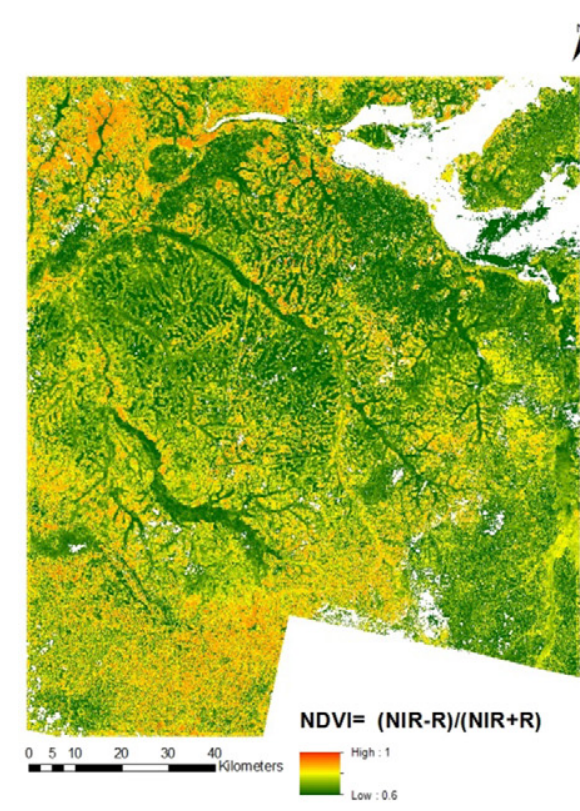

NDVI

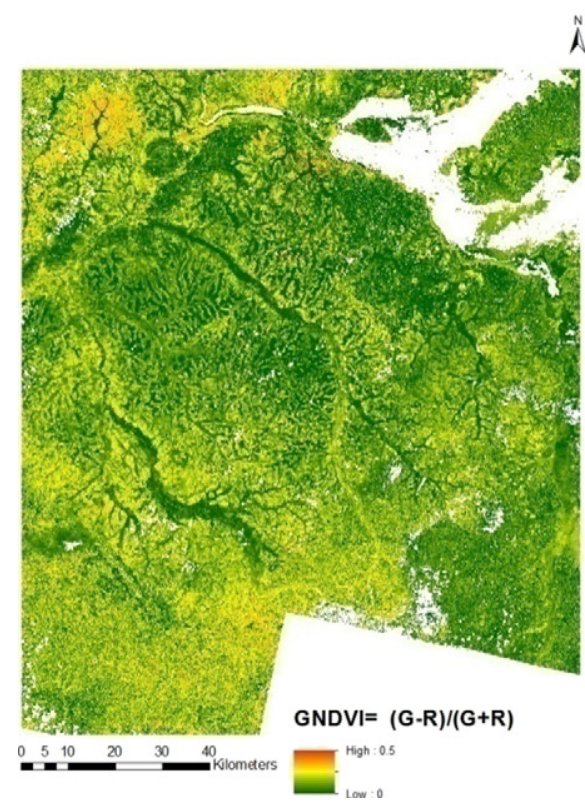

GNDVI
A

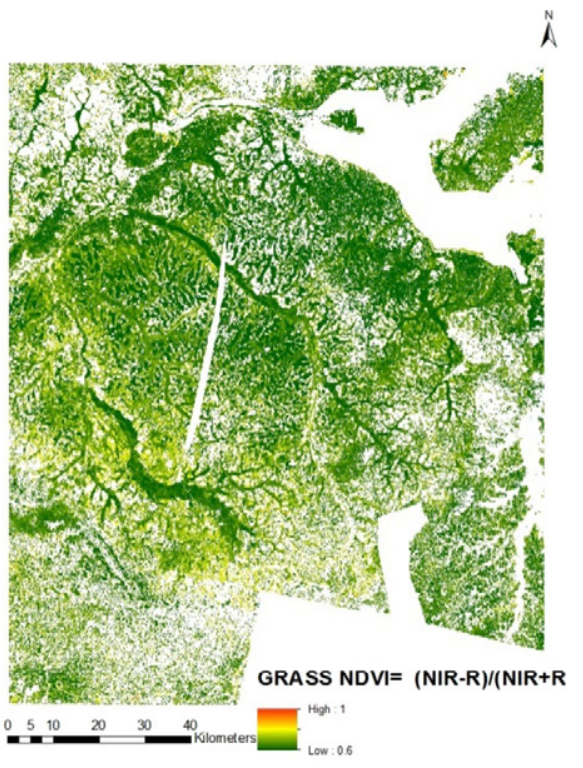

NDVI for grass patches

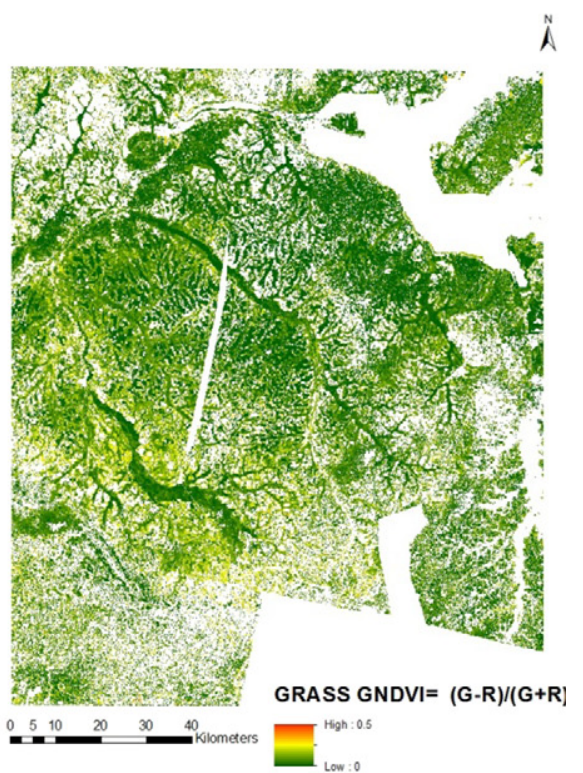

GNDVI for grass patches

Figure 7. Patterns of NDVI and GNDVI at peak vegetation production (November 2014) in the Cattle Corridor of Uganda. 


\section{Step 3 - Cloud Removal}

Band math in ENVI was used to find the sum of the blue, red, and NIR bands. A threshold value was applied to mask out the cloud-free portions of the image (see Fig. 4 for the detailed process). After cloud removal from various image scenes of the region, the new cloud-free scenes were mosaicked, as shown in Figure 5.

\section{Step 4 - Vegetation Type Cover Classification}

Maximum likelihood support vector machine (SVM) (random forest $[\mathrm{RF}]$ algorithm) was used to classify the image into grass and tree pixels (Fig. 6). We recommend the use of SVM or RF because of the high intraclass variability. The area was classified into pasture (grasslands) that included crop areas and seasonally flooded wetlands and woodlands. Training and validation was obtained from field sampling and Google Earth.

The classification using the SVM classifier produced an overall accuracy of 82\%: grasslands and farms (producer accuracy $=97 \%$, user accuracy $=60 \%$ ); woodlands (producer accuracy $=91 \%$, user accuracy $=99 \%$ ); and vegetated riverbeds (producer accuracy $=73 \%$, user accuracy $=95 \%)$. The low accuracy of grassland was due to the classification of vegetated riverbeds as grassland, which was understandable because most of the riverbeds were grasslands.

\section{Step 5 - NDVI Images}

To highlight patterns in vegetation and grass condition, the traditional NDVI (NIR-R)/(NIR $+\mathrm{R})$ and green NDVI or GNDVI $(G-R) /(G+R)$, where $G$ and $R$ are the reflectance in the green and red bands, respectively, were calculated from the Landsat mosaic (Fig. 7). The vegetation index value increases with increasing vigor (e.g., amount of leaf chlorophyll of the vegetation). It is also well established that the nutrient (e.g., leaf $\mathrm{N}$ ) content of grass generally increases with increasing chlorophyll.

\section{Step 6 - Field Sampling of LAI and Grass Biomass}

Fieldwork was conducted in the area to collect data on LAI and fresh and dry biomass. LAI was measured using the plant canopy analyzer (LAI 2200; LI-COR Inc), a handheld optical device. Aboveground fresh biomass (grass) was harvested and immediately weighed. A sensitive balance (at least $\pm 10 \mathrm{~g}$ ) was used for the measurement. The fresh grass for each sample was placed in a paper bag and oven dried at $60^{\circ}$ to $70^{\circ} \mathrm{C}$ for 24 hours before measurement of the dry biomass.

Field LAI data were collected for only 10 randomly selected plots because the LAI 2200 was available for only 1 day. The fresh and dry biomass data were measured for five other plots. The data were used to establish the relationship (predictive model) between LAI and fresh or dry biomass in the region (see Fig. 8 for November 2014). We assumed that these relationships were generic in nature and were used to convert LAI measurements to biomass. The power functions (predictive models) in Figure 8 were preferred to the linear predictive models because they could be extrapolated to predict realistic values for biomass below LAI of 1 . The linear model for LAI values predicted negative biomass values. The
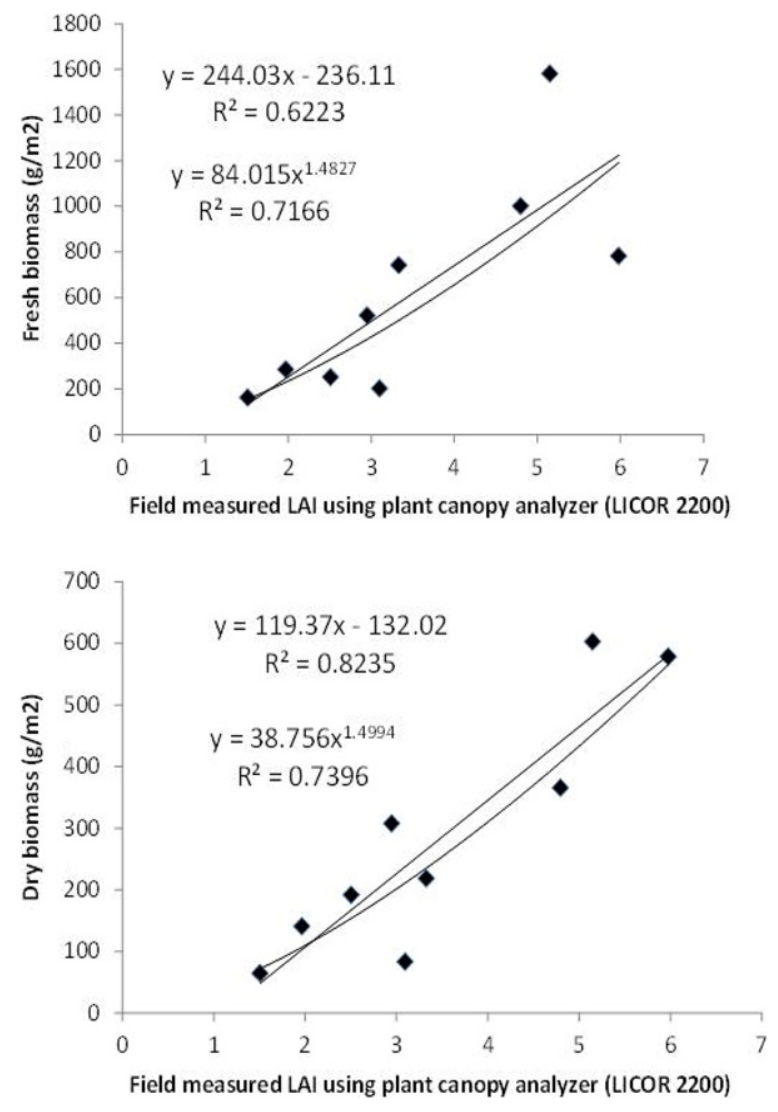

Figure 8. Relationship between field-measured LAl using plant canopy Analyzer (LAl 2200) and fresh grass biomass or dry (oven dry) grass biomass.

mass of the dried grass was about half the mass of fresh grass. The relationship between the fresh and dry mass was also established (Fig. 9).

\section{Step 7 - Radiative Transfer Modeling and Developing Predictive Equation for LAI}

The PROSAIL-5 radiative transfer model was used to simulate 3000 spectral reflectance, mimicking the Landsat 8 reflectance spectra of the project area. PROSAIL had a combination of PROSPECT (a leaf optical properties model) and SAIL (a four-stream canopy RTM). ${ }^{14,15}$ Figure 10 shows

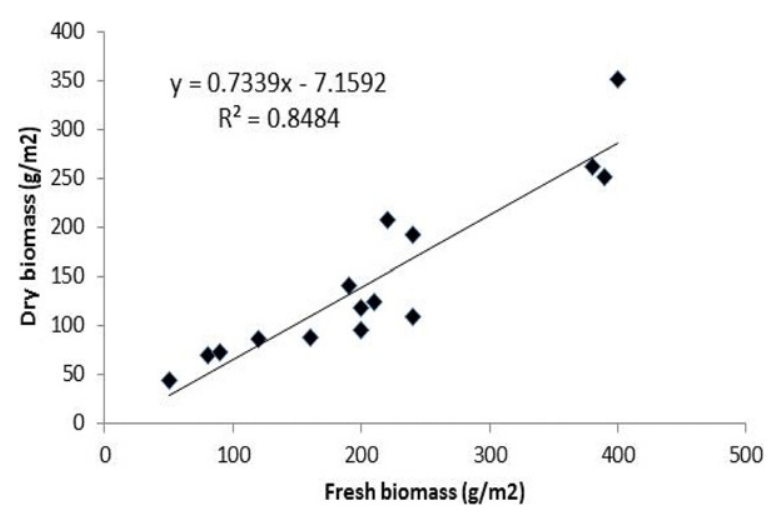

Figure 9. Relationship between fresh grass biomass and dry biomass. 


\begin{tabular}{|c|c|c|c|c|c|}
\hline Chlorophyll : & Uniform - & Min: & 0.0000 & Max: & 90.000 \\
\hline Leaf Area Index: & Uniform $\rightarrow$ & Min: & 0.0000 & Max: & 8.0000 \\
\hline Carotenoid Content : & Uniform - & Min: & 0.0000 & Max: & 25.000 \\
\hline Total Brown Pigment : & Uniform $\rightarrow$ & Min: & 0.0000 & Max: & 1.0000 \\
\hline Equivalent Water Thickness & Uniform - & Min: & 0.0040 & Max: & 0.0400 \\
\hline Dry Matter Content : & Uniform - & Min: & 0.0019 & Max: & 0.1650 \\
\hline Leaf Structure Param. $(\mathrm{N})$ : & Normal - & Mean: & 1.2000 & Std: & 0.3000 \\
\hline Average Leaf Angle (Deg.): & Uniform - & Min: & 25 & Max: & 80 \\
\hline Hot Spot : & Normal - & Mean: & 0.2000 & Std: & 0.0100 \\
\hline Viewing Zenith Angle (Deg.) : & Uniform - & Min: & 0 & Max: & 35 \\
\hline Solar Zenith Angle (Deg.): & Uniform - & Min: & 35 & Max: & 60 \\
\hline Rel. Azimuth Angle (Deg.) : & Uniform - & Min: & 35 & Max: & 60 \\
\hline Soil Coefficient & Uniform - & Min: & 0.0000 & Max: & 1.0000 \\
\hline Diffuse Fraction : & 0.70 & & & & \\
\hline
\end{tabular}

Figure 10. Parameter ranges for forward modeling of PROSAIL (i.e., for the simulation of synthetic spectra).
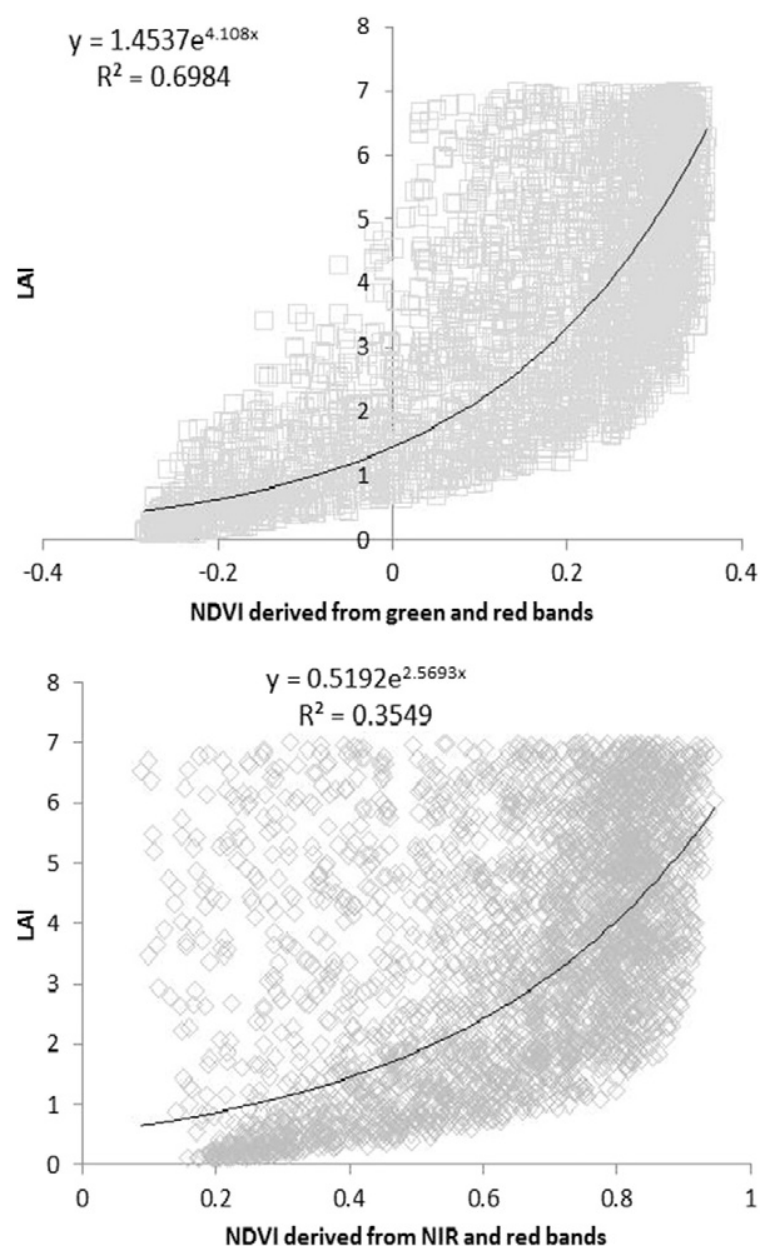

Figure 11. Predictive model of $L A I$ derived from simulated spectra using PROSAIL radiative transfer model.

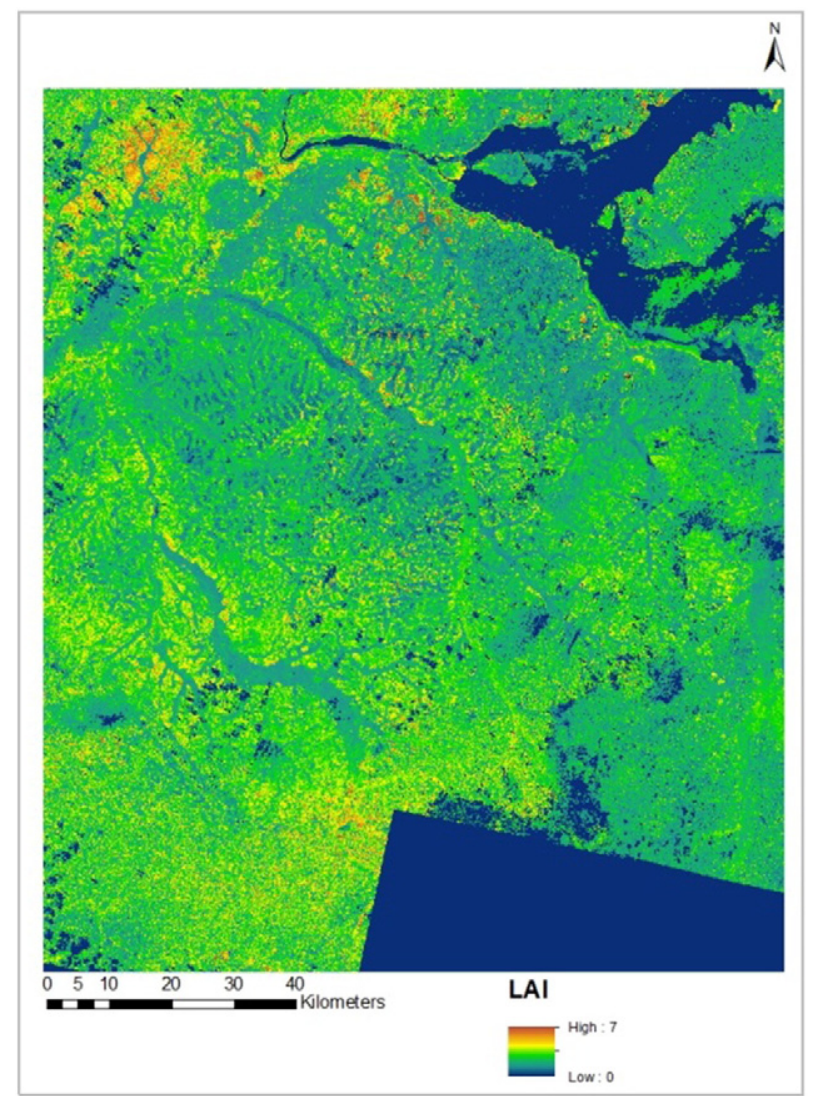

Figure 12. LAI map of the region.

the input parameters used in the forward modeling of PROSAIL. PROSAIL-5B was downloaded from http:// teledetection.ipgp.jussieu.fr/prosail/. ${ }^{16}$ The simulated models were achieved in Matlab.

NDVI $(\mathrm{NIR}-\mathrm{R}) /(\mathrm{NIR}+\mathrm{R})$ and GNDVI $(\mathrm{G}-\mathrm{R}) /(\mathrm{G}+\mathrm{R})$ values were derived from the simulated spectra. A predictive model between LAI and NDVI or GNDVI was made using simulated data. The green NDVI derived from the green and red bands provided a better fit $\left(\mathrm{R}^{2}=0.70\right)$ when compared

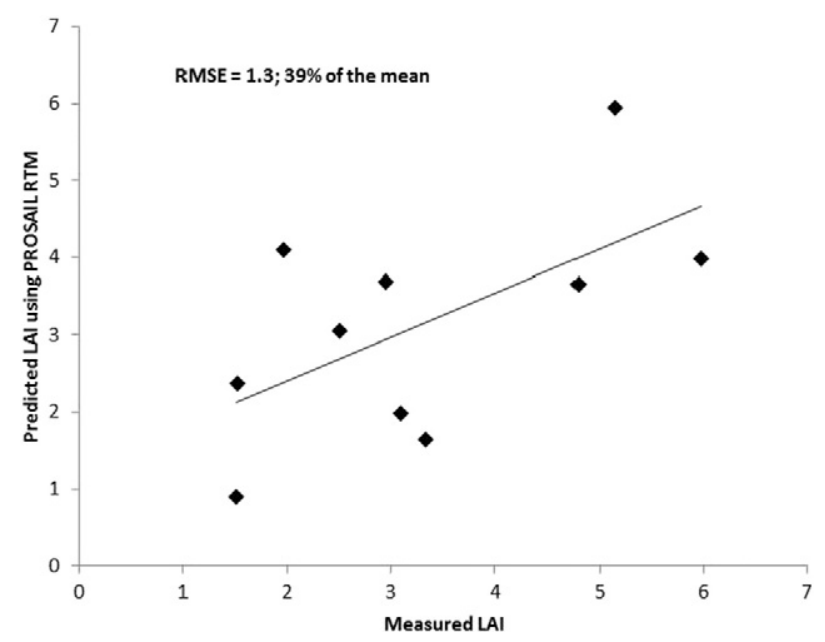

Figure 13. Correlation between measured and predicated LAI. 


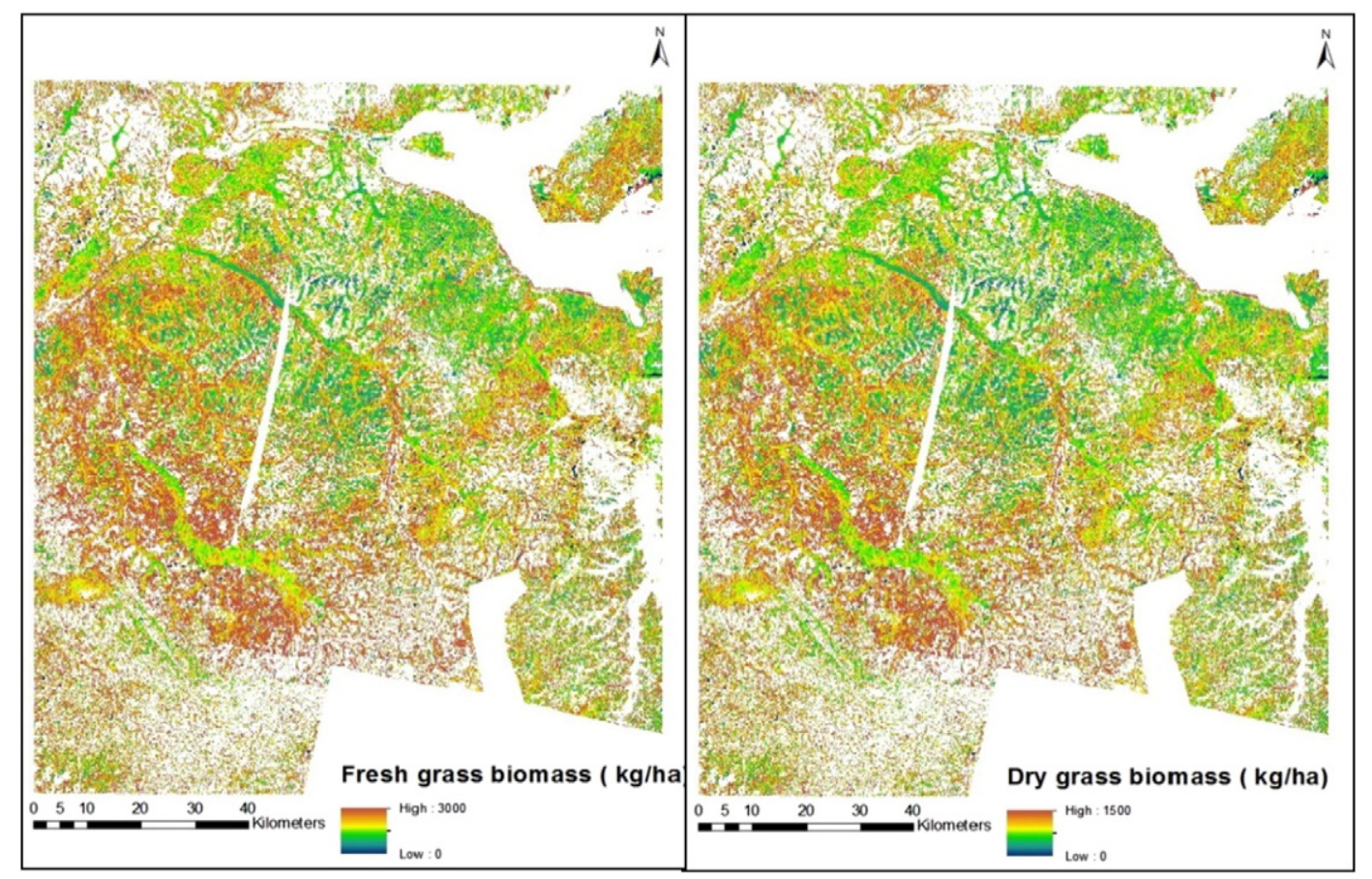

Figure 14. Grass biomass maps derived for the project area.

with the traditional NDVI derived from the NIR and red reflectance $\left(R^{2}=0.35\right)$. The predictive equations are shown on the graphs in Figure 11. These predictive models were used to predict LAI on the satellite image.

\section{Step 8 - Predicting LAI on the Landsat Image}

First, a GNDVI image (the green NDVI in this project provided higher accuracies when compared with the traditional NDVI) was derived from the Landsat data. Second, we used grass class mask derived from the vegetation type map established in step 4 to mask out the grass areas on the NDVI image. The LAI predictive model developed from the PROSAIL data (Step 6) was inverted on the Landsat GNDVI image to predict LAI from the Landsat 8 image (Fig. 12).
The LAI map was produced by inverting the predictive model between the green NDVI derived from the simulated data using the PROSAIL model:

$$
\begin{gathered}
\mathrm{Y}=1.437 \mathrm{e}^{4.108 \mathrm{x}} \\
\mathrm{R}^{2}=0.6984
\end{gathered}
$$

LAI was predicted with a root mean square error (RMSE) of 1.28 ( $39 \%$ of the mean), that is, the error between the predicted LAI using the PROSAIL RTM and the field measured LAI (Fig. 13). We recommend the use of many more points to validate the predicted LAI.

\section{Step 9 - Predicting Grass Biomass}

A grass biomass map was produced from the LAI map by applying the biomass/LAI model established between the
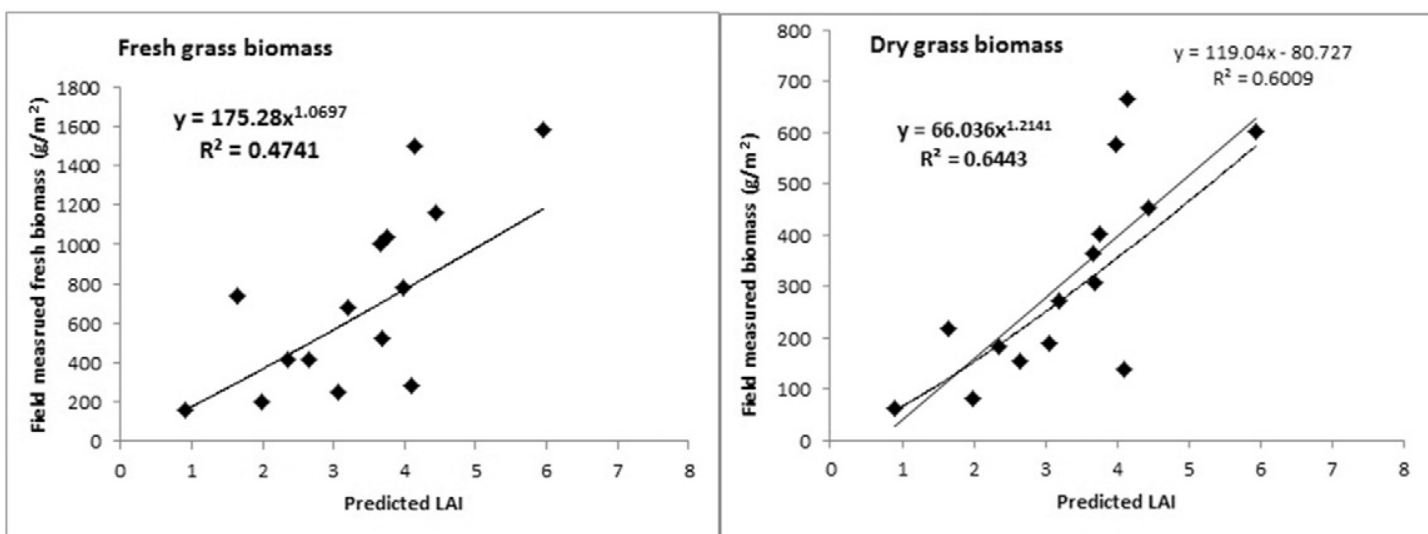

Figure 15. Fresh and dry (oven dry) grass biomass of the region. 


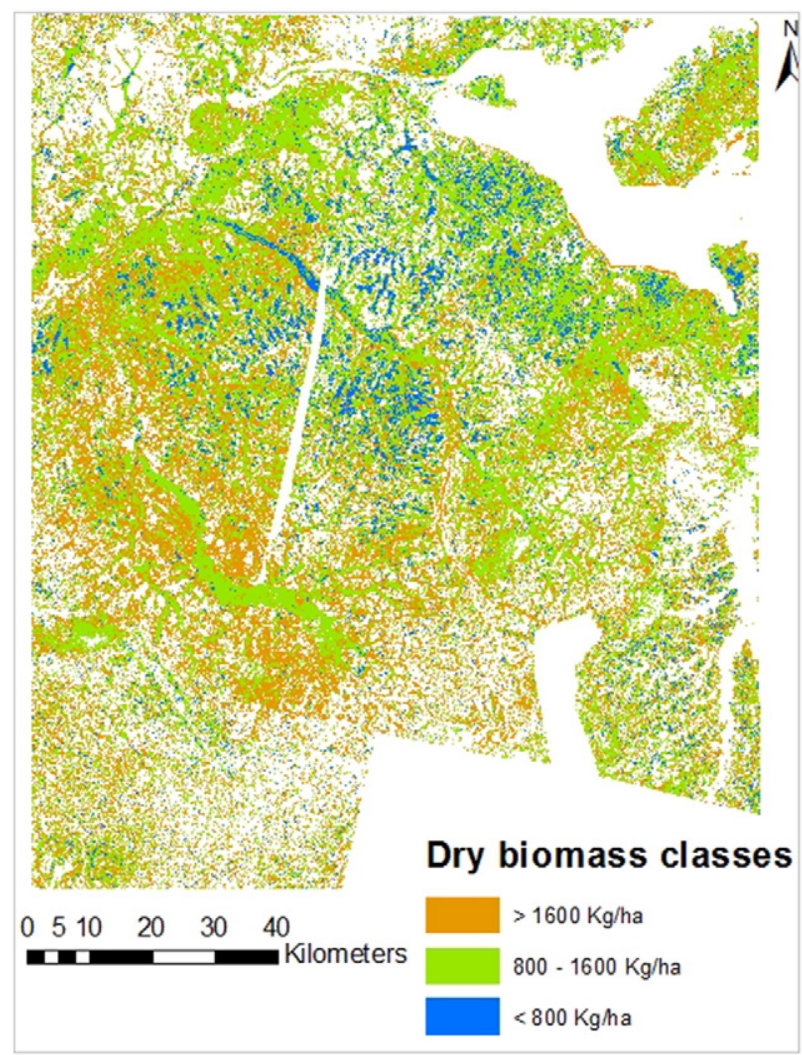

Figure 16. Three grass biomass classes (vector map).

field measured biomass and LAI (Fig. 8). The units were converted from $\mathrm{g} / \mathrm{m}^{2}$ to $\mathrm{kg} /$ ha by multiplying $\mathrm{g} / \mathrm{m}^{2}$ by 10 (i.e., $1 \mathrm{~g} / \mathrm{m}^{2} \rightarrow 10 \mathrm{~kg} / \mathrm{ha}$ ). The strength of the relationship between the predicted LAI and field-measured fresh or dry mass was assessed as shown in Figure 14. A stronger relationship was observed for the dry mass $\left(\mathrm{R}^{2}=0.60\right)$ when compared with the fresh mass $\left(R^{2}=0.47\right.$; Fig. 15).

\section{Accuracy Estimation}

The RMSE between the predicted biomass and field-measured biomass was assessed. The RMSE was lower for the dry mass (121 $\mathrm{kg} / \mathrm{ha} ; 39 \%)$ compared with the fresh biomass (323 kg/ha; 45\%).

The grass biomass map was binned into several classes (e.g., low, medium, and high biomass classes), as shown in Figure 16, to highlight the regions of high production. The central and western region showed the highest biomass during October to November 2014.

\section{Discussion}

The best period for hay harvesting and available hay using RS data indeed coincides with the rainfall season in the Cattle Corridor of Uganda. Most of the areas in the Cattle Corridor, including the study area, largely receive a bimodal rainfall. ${ }^{17}$ This implies that the harvest of hay in the Cattle Corridor should be shortly after the rainfall peaks in May and toward the end of November and beginning of December in the seasonal calendar year. However, the rainfall increasingly is highly variable. This trend agrees with studies done in the Cattle Corridor of Uganda, which receives rainfall between 500 and $1000 \mathrm{~mm}$ annually. ${ }^{3,6}$ The implication of this has been a more sedentary lifestyle in the Cattle Corridor. This, therefore, presents an opportunity for haymaking, but it also presents the challenge of increased pressure on the available resources.

Modeling hay production quantity brings out the importance of GIS and RS in mapping of potential hay areas. Use of geospatial technology (GIS and RS) in haymaking highlights the importance of optimizing hay production in rural rangelands, and the findings indeed substantiate the findings presented in the paper. This shows the usefulness of such tools and, if integrated with different spatial environmental and socio-economic variables such as climate, topography, geology, soils, drainage patterns, road networks, and population, presents an important tool for decision-making and investment. ${ }^{11}$ Boyd \& Foody (2010) provide similar observation from recent research in ecological informatics involving $\mathrm{RS}$ and GIS. We need to focus on a selected range of issues including topics such as the nature of RS data sets, issues of accuracy and uncertainty, data visualization and sharing activities, as well as developments in aspects of ecological modeling research. Indeed, considerable advances have been made over recent years and foundations for future research established.

This methodology (step-by-step modeling) provides a rapid tool for data collection, minimizing fieldwork and hence reducing the cost of obtaining critical information. The steps in modeling hay quantity present a new methodology for monitoring biomass production in semi-arid areas such as the Cattle Corridor of Uganda. With this, plans can be made for when, where, and how much to harvest. In addition, this methodology provides an adaptation approach/coping strategy for the increased changes in climate in such areas. From the findings and field observations, there is high spread of woody species that affect grasslands. Other studies have observed the same thing: One major challenge in the management of rangeland ecosystems is the perceived widespread encroachment of woody species, which reduce grazing area, suppress palatable grass species, and increase production costs. ${ }^{18}$ Woody encroachment is often associated with alteration of above- and below-ground productivity, litter quality, altered hydrology, and changes in microclimate and earth's surface albedo, among others. ${ }^{19}$ Moving forward, the next step is to map species type and nutrient value of these species. Some technologies and satellite data are available that can be used to map hay species type and quality.

\section{Conclusions}

In conclusion, this study presents a methodology that may guide livestock managers, extension workers, and farmers in 1) determining the best period for hay harvest corresponding to peak productivity of the vegetation in rangelands, 2) estimating the amount of hay available (biomass) at peak productivity, using commonly available satellite imagery, 
and 3) highlighting the best areas for hay production based on grassland availability. It is recommended that this methodology (monitoring framework for hay mapping) be scaled up to regional scales so we are able to map biomass areas and hence potential hay making areas over wider areas. It is recommended that further studies be done taking into consideration separation of non-grass biomasses from the total vegetative biomass.

\section{Acknowledgments}

We appreciate the technical assistance and support from the Council for Scientific and Industrial Research (CSIR) of South Africa and the Uganda National Agricultural Research Organisation-National Livestock Resources Research Institute (NARO-NALiRRI).

\section{References}

1. Mallikarjuna, K.G. 2013. Food security and climate change. Res Appl, Nat Soc Sci (IJRANSS) 1(1):45-52 of (Pg 1-58).

2. SivandRAN, G., AND R.L. BRAS. 2012. Identifying the optimal spatially and temporally invariant root distribution for a semiarid environment. Water Resour Res 48(12), https://doi.org/ 10.1029/2012WR012055.

3. Makuma-Massa, H., J.G.M. Majaliwa, P. Isubikalu, C. Nandozi, P. Mukwaya, L. Aribo, and E. Adipala. 2012. Vegetation biomass prediction in the Cattle Corridor of Uganda. Afr Crop Sci J 20(s2):587-599.

4. Hepworth, N., And M. Goulden. 2008. Climate change in Uganda: Understanding the implications and appraising the response. Edinburgh: LTS International. Available at: http:// reliefweb.int/sites/reliefweb.int/files/resources/ 7F1BF4A7CF37F6A54925756F0016ED29-Full_Report.pdf.

5. KABASSA, J. 2008. Weather, climate and climate change in national development sub-sector. Consultancy Report submitted to the Ministry of Water. Kampala Uganda: Land and Environment.

6. Egeru, A., O. Wasonga, J . K yagulany, G.M. Majaliwa, L. MacOpiYo, and J. Mburu. 2014. Spatiotemporal dynamics of forage and land cover changes in Karamoja sub-region, Uganda. Pastoralism 4(1):6.

7. \& Niamir-Fuller, editor. Managing mobility in African rangelands: The legitimization of transhumance. London: Intermediate Technology Publications.

8. Corriher, V., T. Provin, And L. Redmon. 2010. Hay production in Texas (Extension Publication E-273). College Station, TX: Texas A\&M AgriLife Communications.

9. Baival, B., And M.E. Fernández-Giménez. 2012. Meaningful learning for resilience building among Mongolian pastoralists. Nomadic Peoples 16(2):53-77.

10. Suleimenov, M., and P. Oram. 2000. Trends in feed, livestock production, and rangelands during the transition period in three Central Asian countries. Food Policy 25(6):681-700.

11. Boyd, D.S., AND G.M. Foody. 2010. An overview of recent remote sensing and GIS based research in ecological informatics. Ecol Inform 6(1):25-36.
12. Thakur, J.K., S.K. Singh, and S.V. Ekanthalu. 2017. Integrating remote sensing, geographic information systems and global positioning system techniques with hydrological modeling. Appl Water Sci 7(4):1595-1608.

13. United States Geological Survey. Available at: http:// earthexplorer.usgs.gov/. Accessed 29 October and 16 November 2014.

14. Verhoef, W. 1984. Light scattering by leaf layers with application to canopy reflectance modeling: The SAIL model. Remote Sens Environ 16(2):125-141.

15. JaCQUemoud, S ., AND F. BARET. 1990. PROSPECT: A model of leaf optical properties spectra. Remote Sens Environ 34(2):75-91.

16. PROSPECT+SAIL = PROSAIL. Available at: http:// teledetection.ipgp.jussieu.fr/prosail/. Accessed 29 October 2014.

17. National EnVIRONMENT AND Management Authority (NEMA), 2008. State of the environment report for Uganda. Kampala, Uganda: National Environment and Management Authority.

18. ByenkyA, G.S. 2004. Impact of undesirable plant communities on the carrying capacity and livestock performance in pastoral systems of South-Western Uganda. [thesis]. College Station, TX, USA: Texas A\&M University.

19. Chapin, F.S., M. Sturm, M.S erreze, J . M cFadden, AND J. KeY. 2005. Role of land-surface changes in arctic summer warming. Science 310:657-660.

Authors are Program Officer, Grants-RUFORUM (Regional Universities Forum for Capacity Building in Agriculture), Makerere University, Dept of Environmental Management, Kampala, Uganda (Makuma-Massa, henrimassa@yahoo.com; massahenri@gmail.com); Executive Director, ESIPPS Interna-tional Ltd, Kampala Uganda (Bemigisha); Associate, ESIPPS International Ltd, Kampala Uganda (Kyasimire); Social Econ-omist, ESIPPS International Ltd, Kampala Uganda (Nyirama-horo); GIS Specialist, ESIPPS International Ltd, Kampala Uganda (Begumana); Research Officer, National Livestock Resources Research Institute, Tororo, Uganda and Makerere University, Dept of Environmental Management, Kampala, Uganda (Swidiq); Collaborating Research Fellow, Makerere University, Dept of Environmental Management, Kampala, Uganda and Regional Universities Forum for Capacity Building in Agriculture (RUFORUM), Wandegeya, Uganda (Egeru); and Principal Researcher, Council for Scientific and Industrial Research (CSIR), Pretoria and Dept of Plant and Soil Science University of Pretoria (Cho). We acknowledge financial support from United States Agency for International Development (USAID) and National Aeronautics and Space Administration (NASA) through the SERVIRAFRICA programme implemented by the Regional Centre for Mapping of Resources for Development (RCMRD). 